\title{
An Improved Model of Variable Fuzzy Sets with Normal Membership Function for Crane Safety Evaluation
}

\author{
Aihua Li and Zhangyan Zhao \\ School of Logistics Engineering, Wuhan University of Technology, Wuhan 430063, China \\ Correspondence should be addressed to Zhangyan Zhao; 13871001982@163.com
}

Received 26 October 2016; Revised 10 January 2017; Accepted 7 February 2017; Published 28 February 2017

Academic Editor: Benjamin Ivorra

Copyright (c) 2017 Aihua Li and Zhangyan Zhao. This is an open access article distributed under the Creative Commons Attribution License, which permits unrestricted use, distribution, and reproduction in any medium, provided the original work is properly cited.

\begin{abstract}
Crane safety evaluation is significant for reducing the casualties and economic losses. Various evaluation methods have been applied to evaluate crane safety. However, when index standard with respect to every level is described in terms of intervals, existing crane safety evaluation models are not ideal. Although variable fuzzy sets (VFS) method has successfully solved similar problems, its evaluation processes are rather complex complicated and tedious. In this paper, we provided an improved VFS evaluation method with normal membership function for solving crane safety problem, in which the evaluation criteria are described in terms of intervals. To demonstrate our presented method, the improved variable fuzzy sets (IVFS) method was applied to two numerical cases including an application to crane safety assessment. It is shown that our proposed method possesses the merit to simplify assessment processes of traditional VFS and can be applied to assess crane safety when criteria values are defined as interval numbers.
\end{abstract}

\section{Introduction}

As a high-risk special equipment, crane has been widely used in industrial and mining enterprises, real estate, ports, railway transportation, and so forth [1]. Its safety problems constituted a great threat to people's life and property. According to the record from US Labor Statistics, there were 632 cranerelated construction worker deaths from 1992 to 2006 in the United States [2]. Besides, there were 41 fatalities resulting from crane accidents in 2006 in Japan [3]. Only in the year of 2015, China recorded 79 crane accidents, accounting for $30.74 \%$ of the total special equipment accidents [4]. Crane safety problems have been received extensive attention $[5,6]$.

In order to guarantee the safety of the crane, many fuzzy theories and methods have been employed to assess crane safety such as fuzzy AHP [7, 8], 3-scale AHP [9], uncertainty measurement theory $[10,11]$, and grey theory [12]. Although fuzzy mathematics methods possess the advantages of simple calculation and easy understanding, but these evaluation models rely heavily on experts' judgments and their personal experiences. In recent years, the intelligent evaluation methods based on machine learning, such as BP artificial neural network [13], fuzzy neural network [14], support vector machine [15], and Fisher discriminance and analysis method [16], were applied in the crane safety evaluation, but these artificial intelligent assessment approaches depend on reliable and typical samples which are often unavailable, so as to restrict its application. In practice, fuzzy evaluation methods are most commonly used in crane safety assessment. However, existing crane safety evaluation models are not ideal, when index standard with respect to every level is described in terms of interval. As a matter fact, in many applications, evaluation standards of crane index are given as intervals $[17,18]$. To solve the problem, new assessment model for crane safety should be deeply investigated.

Fortunately, VFS proposed by Chen can successfully deal with similar problems [19]. It has been widely applied in such fields as flood control systems evaluation [20], agricultural drought risk assessment [21], and water quality assessment [22]. However, its calculation is complicated and tedious $[23,24]$. In spite of the fact that Wu's set pair analysis-variable fuzzy sets (SPA-VFS) method [23] simplifies assessment processes, some concepts of SPA are not easy to understand and the calculation of RMD is not very intuitive. This will 
be illustrated in Section 4 through the examination of a case. To make up the insufficiency of VFS and SPA-VFS evaluation methods discussed above, we attempt to propose an improved VFS evaluation method, by using normal membership functions to calculate relative membership degrees, and apply the new model to crane safety assessment.

The rest of this paper is organized as follows. Section 2 introduces the traditional VFS assessment method. Section 3 presents entropy weight method and the IVFS model with normal membership function. Section 4 investigates two cases involving an application to crane safety assessment and makes some comparison analysis. Finally, Section 5 offers the conclusions.

\section{Traditional VFS Assessment Method}

2.1. Variable Fuzzy Sets. In 2009, Chen developed variable fuzzy sets theory [20] based on engineering fuzzy sets [25] and the relative difference function [26], which broke through the static fuzzy set [27] established by Zadeh without considering the dynamic changing process of things. Variable fuzzy sets theory is described briefly as follows.

Let $X$ be a fuzzy concept and $\underset{\sim}{A}$ and $A^{c}$ represent the acceptability and repellency, respectively. For any element $x$ in $X, \mu_{A}(x)$ and $\mu_{A^{c}}(x)$ are the relative membership degrees $(\mathrm{RMD})$ of $x$ to $\underset{\sim}{A}$ and $\underline{\sim}^{c}$, and $\mu_{\mathcal{A}^{A}}(x)+\mu_{\mathcal{A}^{c}}(x)=1,0 \leq \mu_{\mathcal{A}^{A}}(x) \leq$ $1,0 \leq \mu_{\mathcal{A}^{c}}(x) \leq 1$. Suppose $\tilde{D}_{\mathcal{A}^{A}}(x)=\widetilde{\mu}_{\mathcal{A}}(x)-\mu_{\tilde{A}^{c}}(x)$, where $D_{A}(x)$ is the relative difference degree (RDD) of $x$ to $\underset{A}{A}$ and $A^{\widetilde{c}}$. Mapping $D: x \rightarrow D(x) \in[-1,1]$ is defined as the relative difference degree (RDD) of $x$ to $A$. Therefore, the relationship of $\mathrm{RDD}$ and the RMD is

$$
\begin{gathered}
D_{\mathcal{A}}(x)=2 \mu_{\underline{A}}(x)-1, \\
\text { or } \mu_{\underline{A}}(x)=\frac{\left(D_{\underline{A}}(x)+1\right)}{2} .
\end{gathered}
$$

Let

$$
\begin{aligned}
V & =\left\{(x, D) \mid x \in X, D_{\underline{A}}(x)=\mu_{\underline{A}}(x)-\mu_{\mathcal{A}^{c}}(x), D\right. \\
& \in[-1,1]\}, \\
A_{+} & =\left\{x \mid x \in X, 0<D_{\mathcal{D}_{A}}(x)<1\right\}, \\
A_{-} & =\left\{x \mid x \in X,-1<D_{D_{A}}(x)<0\right\}, \\
A_{0} & =\left\{x \mid x \in X, D_{\mathcal{A}_{A}}(x)=0\right\},
\end{aligned}
$$

where $V$ is defined as VFS of $X$, and $A_{+}, A_{-}$, and $A_{0}$ are defined as attracting sets, repelling sets, and balance boundary of VFS $V$, respectively [19].

2.2. Relative Difference and Membership Degree Function. We suppose that $X_{0}=[a, b]$ is attraction domain of $V$ on the real axis. And $X$ is a certain interval $[c, d]$ containing $X_{0}\left(X_{0} \subset\right.$ $X$ ) (see Figure 1). Based on the definition of VFS, we can infer

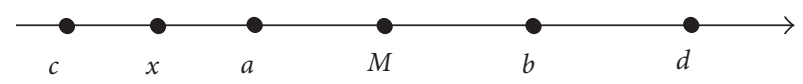

FIGURE 1: Location relationship between points $x, M$ and $X_{0}, X$.

that the intervals $[c, a]$ and $[b, d]$ are both exclusive domains; that is, $-1<D_{A}(x)<0$. Suppose that $M$ is point value of $D_{A^{A}}(x)=1\left(\tilde{\mu}_{A}(x)=1\right)$ in attracting domain $[a, b] . x$ is a random point in interval $X$. If $x$ locates on the left side of $M$, relative difference degree function $D_{A}(x)$ and relative membership degree function $\mu_{\mathcal{A}}(x)$ are as follows [32, 33]:

$$
\begin{aligned}
& D_{\sim}(x)=\left(\frac{x-a}{M-a}\right), \quad x \in(a, M), \\
& D_{\sim}(x)=-\left(\frac{x-a}{c-a}\right), \quad x \in(c, a) ; \\
& \mu_{\sim}(x)=0.5\left(1+\frac{x-a}{M-a}\right), \quad x \in(a, M), \\
& \mu_{\sim}(x)=0.5\left(1-\frac{x-a}{c-a}\right), \quad x \in(c, a) ;
\end{aligned}
$$

If $x$ locates on the right side of $M, D_{\mathcal{A}_{A}}(x)$ and $\mu_{\mathcal{A}}(x)$ are

$$
\begin{aligned}
& D_{\underline{A}}(x)=\left(\frac{x-b}{M-b}\right), \quad x \in(M, b), \\
& D_{\underline{A}}(x)=-\left(\frac{x-b}{d-b}\right), \quad x \in(b, d) ; \\
& \mu_{\sim}(x)=0.5\left(1+\frac{x-b}{M-b}\right), \quad x \in(M, b), \\
& \mu_{\mu_{A}}(x)=0.5\left(1-\frac{x-b}{d-b}\right), \quad x \in(b, d) .
\end{aligned}
$$

2.3. Synthesis Relative Membership Degree Function. Suppose there are $m(i=1,2, \ldots, m)$ indexes and $k(h=1,2, \ldots, k)$ levels, synthesis relative membership degree [34] can be calculated by

$$
\beta_{i h}(x)=\left\{1+\left[\frac{\sum_{i=1}^{m}\left[w_{i}\left(1-\mu_{i h}(x)\right)\right]^{p}}{\sum_{i=1}^{m}\left[w_{i} \mu_{i h}(x)\right]^{p}}\right]^{\alpha / p}\right\}^{-1},
$$

where $\beta_{i h}(x)$ is the synthetic relative membership degree to level $h ; w_{i}$ is the index weight; $\mu_{i h}(x)$ is the relative membership degree of $i$ th index to level $h ; m$ is the number of index; $h$ is the grade of the evaluation standard; $p$ is a distance parameter. When $p=1$, it is called Hamming distance. When $p=2$, it is Euclidean distance. $a$ is an optimization criterion parameter. When $a=1$, it is least single criterion. When $a=2$, it is least square criterion. There are four combination forms: $p=1, a=1 ; p=1, a=2 ; p=2, a=1 ; p=2, a=2$.

When $p=1, a=1$, (5) can be expressed as follows:

$$
\beta_{i h}(x)=\sum_{i=1}^{m} w_{i} \mu_{i h}(x)
$$




\subsection{Traditional Assessment Steps Based on Variable Fuzzy Sets}

Step 1. According to intervals of evaluation standard to establish the interval criterion matrix $\mathbf{I}_{a b}=\left([a, b]_{i h}\right)$,

$$
\begin{aligned}
\mathbf{I}_{a b}= & \left(\left[a_{i h}, b_{i h}\right]\right) \\
= & \left(\begin{array}{cccc}
{\left[a_{11}, b_{11}\right]} & {\left[a_{12}, b_{12}\right]} & \cdots & {\left[a_{1 k}, b_{1 k}\right]} \\
{\left[a_{21}, b_{21}\right]} & {\left[a_{22}, b_{22}\right]} & \cdots & {\left[a_{2 k}, b_{2 k}\right]} \\
\vdots & \vdots & \vdots & \vdots \\
{\left[a_{m 1}, b_{m 1}\right]} & {\left[a_{m 2}, b_{m 2}\right]} & \cdots & {\left[a_{m k}, b_{m k}\right]}
\end{array}\right),
\end{aligned}
$$

where $i=1,2, \ldots, m ; h=1,2, \ldots, k$.

Step 2. According to the interval criterion matrix $\mathbf{I}_{a b}$ and intervals of evaluation standard to establish variable interval matrix $\mathbf{I}_{c d}$,

$$
\begin{aligned}
\mathbf{I}_{c d} & =\left(\left[c_{i h}, d_{i h}\right]\right) \\
& =\left(\begin{array}{cccc}
{\left[c_{11}, d_{11}\right]} & {\left[c_{12}, d_{12}\right]} & \cdots & {\left[c_{1 k}, d_{1 k}\right]} \\
{\left[c_{21}, d_{21}\right]} & {\left[c_{22}, d_{22}\right]} & \cdots & {\left[c_{2 k}, d_{2 k}\right]} \\
\vdots & \vdots & \vdots & \vdots \\
{\left[c_{m 1}, d_{m 1}\right]} & {\left[c_{m 2}, d_{m 2}\right]} & \cdots & {\left[c_{m k}, d_{m k}\right]}
\end{array}\right),
\end{aligned}
$$

where $i=1,2, \ldots, m ; h=1,2, \ldots, k$.

Step 3. Establish the point value mapping matrix $\mathbf{M}$ :

$$
\mathbf{M}=\left(M_{i h}\right)=\left(\begin{array}{cccc}
M_{11} & M_{12} & \cdots & M_{1 k} \\
M_{21} & M_{22} & \cdots & M_{2 k} \\
\vdots & \vdots & \vdots & \vdots \\
M_{m 1} & M_{m 2} & \cdots & M_{m k}
\end{array}\right),
$$

where $i=1,2, \ldots, m ; h=1,2, \ldots, k$.

Step 4. Establish the RMD matrix $\boldsymbol{\mu}(u)$ based on (1) to (4):

$$
\begin{aligned}
& \boldsymbol{\mu}(x)=\left[\mu_{i h}(x)\right]=\left[\begin{array}{cccc}
\mu_{11}(x) & \mu_{12}(x) & \cdots & \mu_{1 k}(x) \\
\mu_{21}(x) & \mu_{22}(x) & \cdots & \mu_{2 k}(x) \\
\vdots & \vdots & \vdots & \vdots \\
\mu_{m 1}(x) & \mu_{m 2}(x) & \cdots & \mu_{m k}(x)
\end{array}\right], \\
& i=1,2, \ldots, m ; h=1,2, \ldots, k .
\end{aligned}
$$

Step 5. Determine the index weights. In this step, subjective or objective weighting method can be used to calculate index weights. Let index weight vector be

$$
\mathbf{W}=\left(w_{i}\right)=\left(w_{1}, \quad w_{2}, \cdots w_{m}\right), \quad \sum_{i=1}^{m} w_{i}=1 .
$$

Step 6. Calculate the SRMD $\boldsymbol{\beta}(x)$ vector based on (5):

$$
\boldsymbol{\beta}(x)=\left(\beta_{1}(x), \beta_{2}(x), \ldots, \beta_{k}(x)\right)=\left(\beta_{h}(x)\right) .
$$

Step 7. Normalize the SRMD $\beta_{h}(x)$ :

$$
\beta_{h}^{\prime}(x)=\frac{\beta_{h}(x)}{\sum_{h=1}^{k} \beta_{h}(x)} .
$$

Step 8. Calculate the level feature value $H$.

$$
H(x)=\sum_{h=1}^{k} \beta_{h}^{\prime}(x) \times h, \quad(h=1,2, \ldots, k) .
$$

Step 9. Determine the safety level by discrimination rule [20]:

$$
1<H(x) \leq 1.5 \text { it belongs to grade } 1 ;
$$

$h-0.5<H(x) \leq h+0.5$

it belongs to grade $h, h=2,3, \ldots, k-1$;

$k-0.5<H(x) \leq k$, it belongs to grade $k$.

\section{An Improved VFS Assessment Model}

3.1. Entropy Weight. Shannon firstly introduced entropy into information theory [35]. As an objective weighting method, entropy method has been widely in water quality assessment [22], flood risk prioritization [36], intrusion detection system evaluation [37], and so forth. Entropy weighting method can fully use the data provided and objectively reflect the relative importance of each indicator. The entropy value of the $i$ th index can be expressed as

$$
E_{i}=-\frac{\sum_{h=1}^{k} \mu_{i h} \ln \mu_{i h}}{\ln k}, \quad i=1,2, \ldots, m,
$$

where $\mu_{i h}$ is the relative membership degree of $i$ th index to level $h$. To ensure that $\mu_{i h} \ln \mu_{i h}$ has mathematical meaning, $\mu_{i h} \ln \mu_{i h}$ is defined as 0 when $\mu_{i h}=0$ [38].

The entropy weight of the $i$ th index is

$$
w_{i}=\frac{1-E_{i}}{m-\sum_{i=1}^{m} E_{i}}, \quad\left(0 \leq w_{i} \leq 1, \sum_{i=1}^{m} w_{i}=1\right) .
$$

3.2. Improved VFS Assessment Model with Normal Membership Function. Although the traditional VFS assessment model is successfully applied to many fields, the RMD calculation is complicated and tedious. To overcome the drawback mentioned above and simplify evaluation procedures, this paper modified the traditional VFS assessment model by incorporating the normal membership function. Membership function is an important component for comprehensive evaluation. There are variable membership functions. Normal membership function is one of the very popular functions. From Figure 2, it is clearly that the shapes of normal and VFS membership functions are similar. What is more, graphs of normal membership function are smooth and continuous, while graphs of VFS membership function are nonsmooth and piecewise. The property of normal membership function is anticipated to avoid the trouble for selecting piecewise linear membership function to calculate RMD. So this work 


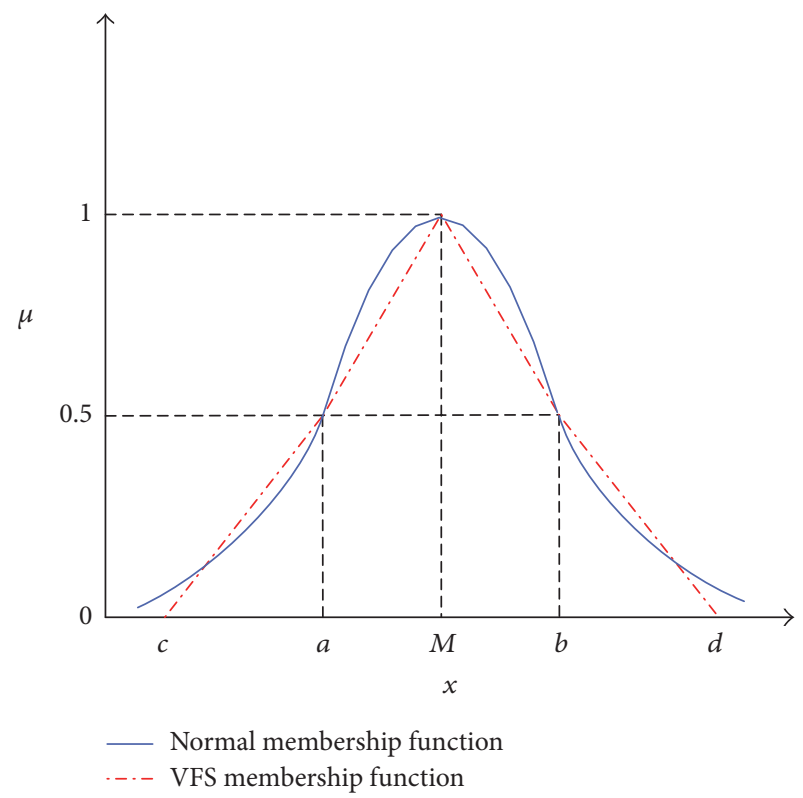

(a)

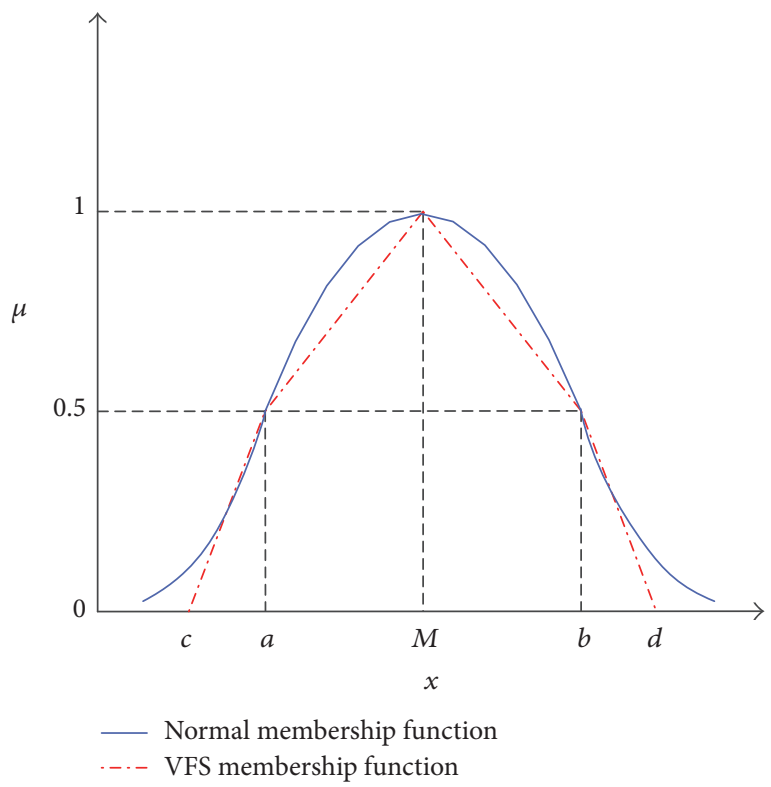

(b)

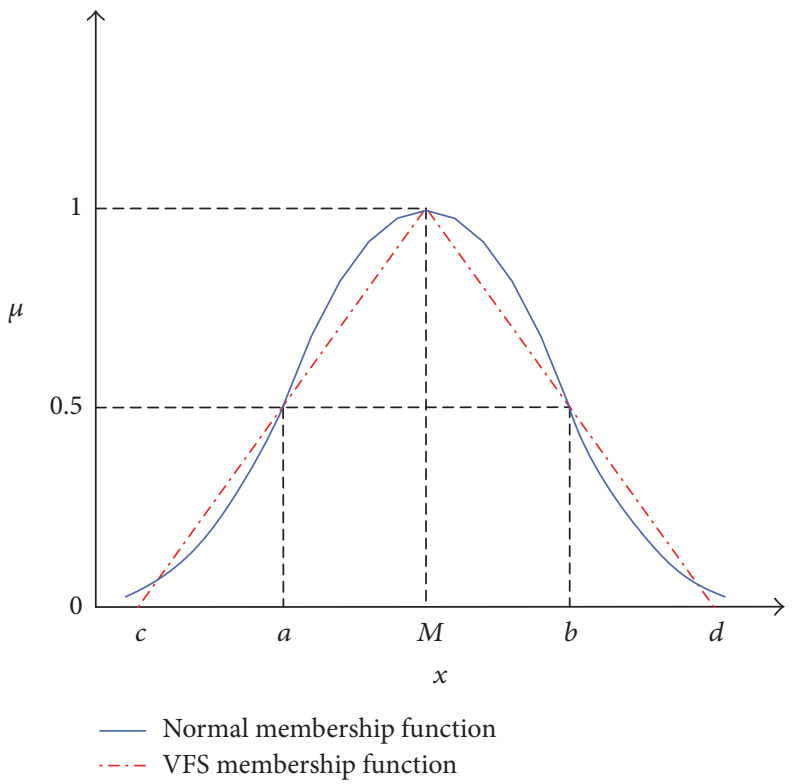

(c)

FIGURE 2: Graphs of normal membership function and VFS membership function: (a) $d-c>2(b-a)$; (b) $d-c<2(b-a)$; (c) $d-c=2(b-a)$.

uses normal membership function to replace traditional VFS membership function. Suppose that $C_{i}$ is $i$ th $(i=1,2, \ldots, m)$ index and the level variable is $h(h=1,2, \ldots, k)$. The figure of normal membership function has symmetry property, which has the desired ability to overcome tedious calculation about RMD in VFS. Therefore, we adopt normal membership function $[39,40]$ to calculate RMD. That is,

$$
\mu_{i h}(x)=\exp \left\{-\left[\frac{(x-t)}{s}\right]^{2}\right\},
$$

where $t$ and $s$ are nonnegative characteristic parameters; $x$ is characteristic value of $i$ th index; $\mu_{i h}(x)$ represent RMD.
(1) Let $x$, index $i$ 's feature value of $u$, belong to level $h(h=2,3 \ldots, k-1)$, according to the evaluation standard intervals $\left[a_{i h}, b_{i h}\right]$; then $\mu_{i h}\left(x=\left(a_{i h}+b_{i h}\right) / 2\right)$ and $\mu_{i h}\left(x=a_{i h}=b_{i h}\right)$ are equal to 1 and 0.5 [41], respectively. Putting $x=\left(a_{i h}+b_{i h}\right) / 2$ and $\mu_{h}(x)=1$ into (18), we have

$$
t=\frac{\left(a_{i h}+b_{i h}\right)}{2}
$$

Substituting (19) into (18), we have

$$
\mu_{i h}(x)=\exp \left\{-\left[\frac{\left(x-\left(a_{i h}+b_{i h}\right) / 2\right)}{s}\right]^{2}\right\} .
$$


Putting $x=a_{i h}\left(\right.$ or $\left.b_{i h}\right)$ and $\mu_{h}\left(x_{i}\right)=0.5$ into (20), we have

$$
s=\frac{\left|a_{i h}-b_{i h}\right|}{2 \sqrt{-\ln 0.5}} .
$$

Putting (19) and (21) into (18), (18) can be rewritten as

$$
\begin{aligned}
& \mu_{i h}(x) \\
& =\exp \left\{-\left[\frac{2 \sqrt{-\ln 0.5}\left(x-0.5 \times\left(a_{i h}+b_{i h}\right)\right)}{a_{i h}-b_{i h}}\right]^{2}\right\} .
\end{aligned}
$$

(2) Let $x$, index $i$ 's feature value of $u$, belong to level 1 $(h=1)$, according to the evaluation standard intervals $\left[a_{1}, b_{1}=a_{2}\right]$; then $\mu_{h=1}\left(x_{i}=a_{1}\right)$ and $\mu_{h=1}\left(x_{i}=b_{1}\right)$ are equal to 1 and 0.5 [41]. Putting $x=a_{1}$ and $\mu_{h}\left(x_{i}\right)=1$ into (18), we have

$$
t=a_{1}
$$

Substituting (23) into (18), we have

$$
\mu_{i 1}(x)=\exp \left\{-\left[\frac{\left(x-a_{1}\right)}{s}\right]^{2}\right\}
$$

Putting $x=b_{1}$ and $\mu_{h}\left(x_{i}\right)=0.5$ into (24), we have

$$
s=\frac{\left|b_{1}-a_{1}\right|}{\sqrt{-\ln 0.5}} \text {. }
$$

Putting (23) and (25) into (18), (18) can be rewritten as

$$
\mu_{i 1}(x)=\exp \left\{-\left[\frac{\sqrt{-\ln 0.5}\left(x-a_{1}\right)}{b_{1}-a_{1}}\right]^{2}\right\} .
$$

(3) Let $x$, index $i$ 's feature value of $u$, belong to level $h$ ( $h=$ $k$ ), according to the evaluation standard intervals $\left[a_{k}=b_{k-1}, b_{k}\right]$; then $\mu_{h=k}\left(x=a_{k}\right)$ and $\mu_{h=k}\left(x_{i}=\right.$ $\left.b_{k}\right)$ are equal to 0.5 and 1 [41], respectively. Putting $x=b_{k}$ and $\mu(x)=1$ into (18), we have

$$
t=b_{k}
$$

Substituting (27) into (18), we have

$$
\mu_{i k}(x)=\exp \left\{-\left[\frac{\left(x-b_{k}\right)}{s}\right]^{2}\right\} .
$$

Putting $x=a_{k}$ and $\mu=0.5$ into (28), we have

$$
s=\frac{\left|b_{k}-a_{k}\right|}{\sqrt{-\ln 0.5}} .
$$

Putting (27) and (29) into (18), (18) can be rewritten as

$$
\mu_{i k}(x)=\exp \left\{-\left[\frac{\sqrt{-\ln 0.5}\left(x-b_{k}\right)}{a_{k}-b_{k}}\right]^{2}\right\} .
$$

According to VFS, RMD $\mu_{i h}$ is larger 0 to attraction domain $[a, b]$ and exclusive domains $[c, a]$ and $[b, d]$, while $\operatorname{RMD} \mu_{i h}$ to other domains is 0 . That is to say, if $x$ locates in the discussed $h$ level, the RMDs to discussed and adjacent levels can be determined by (22), (26), and (30), and the RMDs to the other intensity levels are 0 . Generally, for $k=5$ in this case study, the calculating equations of $\mu_{i h}(i=1,2, \ldots, m$; $h=1,2, \ldots, k=5)$ are as follows.

If $x$ locates in the discussed level 1, the RMDs $\mu_{i h}$ can be calculated by

$$
\begin{aligned}
& \mu_{i(h=1)}(x)=\exp \left\{-\left[\frac{\sqrt{-\ln 0.5}\left(x-a_{1}\right)}{a_{1}-b_{1}}\right]^{2}\right\}, \\
& x \in\left[a_{1}, b_{1}=a_{2}\right], \\
& \mu_{i(h=2)}(x) \\
& =\exp \left\{-\left[\frac{2 \sqrt{-\ln 0.5}\left(x-0.5 \times\left(a_{2}+b_{2}\right)\right)}{a_{2}-b_{2}}\right]^{2}\right\}, \\
& \mu_{i(h=3)}(x)=\mu_{i(h=4)}(x)=\mu_{i(h=5)}(x)=0 .
\end{aligned}
$$

If $x$ locates in the discussed level 2, the RMDs $\mu_{i h}$ can be calculated by

$$
\begin{aligned}
& \mu_{i(h=1)}(x)=\exp \left\{-\left[\frac{\sqrt{-\ln 0.5}\left(x-a_{1}\right)}{a_{1}-b_{1}}\right]^{2}\right\}, \\
& \mu_{i(h=2)}(x) \\
& =\exp \left\{-\left[\frac{2 \sqrt{-\ln 0.5}\left(x-0.5 \times\left(a_{2}+b_{2}\right)\right)}{a_{2}-b_{2}}\right]^{2}\right\}, \\
& x_{i} \in\left[a_{2}=b_{1}, b_{2}=a_{3}\right],
\end{aligned}
$$

$$
\begin{aligned}
& \mu_{i(h=3)}(x) \\
& =\exp \left\{-\left[\frac{2 \sqrt{-\ln 0.5}\left(x-0.5 \times\left(a_{3}+b_{3}\right)\right)}{a_{3}-b_{3}}\right]^{2}\right\}, \\
& \mu_{i(h=4)}(x)=\mu_{i(h=5)}(x)=0 .
\end{aligned}
$$

If $x$ locates in the discussed level 3, the RMDs $\mu_{i h}$ can be calculated by

$$
\begin{aligned}
& \mu_{i(h=1)}(x)=0, \\
& \mu_{i(h=2)}(x) \\
& \quad=\exp \left\{-\left[\frac{2 \sqrt{-\ln 0.5}\left(x-0.5 \times\left(a_{2}+b_{2}\right)\right)}{a_{2}-b_{2}}\right]^{2}\right\},
\end{aligned}
$$


TABLE 1: Measured values of evaluation indicators.

\begin{tabular}{|c|c|c|c|c|c|}
\hline Samples & $\begin{array}{l}\text { Rock mass } \\
\text { quality } C_{1}\end{array}$ & $\begin{array}{l}\text { Uniaxial compressive } \\
\text { strength } C_{2}(\mathrm{MPa})\end{array}$ & $\begin{array}{c}\text { Integrality degree } \\
\text { of rock mass } C_{3} \\
\end{array}$ & $\begin{array}{l}\text { Groundwater percolation capacity } \\
C_{4}(\mathrm{~L} /(\mathrm{min} \cdot 10 \mathrm{~m})) \\
\end{array}$ & Joint $C_{5}$ \\
\hline 1 & 0.12 & 185.5 & 0.89 & 6 & 8 \\
\hline 2 & 0.27 & 176.4 & 0.80 & 8 & 7 \\
\hline 3 & 0.08 & 158.2 & 0.94 & 6 & 7 \\
\hline 4 & 0.04 & 201.1 & 0.97 & 5 & 9 \\
\hline 5 & 0.24 & 181.9 & 0.92 & 9 & 8 \\
\hline
\end{tabular}

$$
\begin{array}{r}
\mu_{i(h=3)}(x) \\
=\exp \left\{-\left[\frac{2 \sqrt{-\ln 0.5}\left(x-0.5 \times\left(a_{3}+b_{3}\right)\right)}{a_{3}-b_{3}}\right]^{2}\right\}, \\
x_{i} \in\left[a_{3}=b_{2}, b_{3}=a_{4}\right],
\end{array}
$$

$\mu_{i(h=4)}(x)$

$$
=\exp \left\{-\left[\frac{2 \sqrt{-\ln 0.5}\left(x-0.5 \times\left(a_{4}+b_{4}\right)\right)}{a_{4}-b_{4}}\right]^{2}\right\}
$$

$\mu_{i(h=5)}(x)=0$.

If $x$ locates in the discussed level 4, the RMDs $\mu_{i h}$ can be calculated by

$$
\begin{aligned}
& \mu_{i(h=1)}(x)=\mu_{i(h=2)}(x)=0, \\
& \mu_{i(h=3)}(x) \\
& =\exp \left\{-\left[\frac{2 \sqrt{-\ln 0.5}\left(x-0.5 \times\left(a_{3}+b_{3}\right)\right)}{a_{3}-b_{3}}\right]^{2}\right\}, \\
& \mu_{i(h=4)}(x) \quad \\
& =\exp \left\{-\left[\frac{2 \sqrt{-\ln 0.5}\left(x-0.5 \times\left(a_{4}+b_{4}\right)\right)}{a_{4}-b_{4}}\right]^{2}\right\}, \\
& x \in\left[a_{4}=b_{3}, b_{4}=a_{5}\right], \\
& \mu_{i(h=5)}(x)=\exp \left\{-\left[\frac{\sqrt{-\ln 0.5}\left(x-b_{5}\right)}{a_{5}-b_{5}}\right]^{2}\right\} .
\end{aligned}
$$

If $x$ locates in the discussed level 5, the RMDs $\mu_{i h}$ can be calculated by

$$
\begin{aligned}
& \mu_{i(h=1)}(x)=\mu_{i(h=2)}(x)=\mu_{i(h=3)}(x)=0, \\
& \mu_{i(h=4)}(x) \\
& \quad=\exp \left\{-\left[\frac{2 \sqrt{-\ln 0.5}\left(x-0.5 \times\left(a_{4}+b_{4}\right)\right)}{a_{4}-b_{4}}\right]^{2}\right\},
\end{aligned}
$$

$$
\begin{array}{r}
\mu_{i(h=5)}(x)=\exp \left\{-\left[\frac{\sqrt{-\ln 0.5}\left(x-b_{5}\right)}{a_{5}-b_{5}}\right]^{2}\right\}, \\
x \in\left[a_{5}=b_{4}, b_{5}\right] .
\end{array}
$$

Using (31)-(35), the RMD matrix $\boldsymbol{\mu}(x)=\left(\mu_{i h}(x)\right)$ can be obtained. Although the normal membership function is a nonlinear model, it can be easily solved by using Microsoft Excel software. Based on the above analysis, the RMD calculation of traditional VFS model was improved with normal membership function. The flow chart of assessment procedure is provided in Figure 3. The evaluation procedure with the proposed approach is as follows:

(1) Establish assessment indexes system and classification standards.

(2) Establish the single index RMD matrix $\boldsymbol{\mu}(x)$ with (31)-(35)

(3) Determine the index weights.

(4) Calculate SRMD to each level with (5).

(5) Normalize the SRMD with (13).

(6) Calculate the level feature value $H$ and determine the assessment level with (14)-(15).

\section{Case Study}

In this section, we examined two numerical cases using the proposed IVFS method. The first case was used to demonstrate the validity and reliability of our approach. Then the second case was the application of the proposed approach to crane metal structure after assessment. Finally, the analysis and comparison of the evaluation results are also conducted to show the superiority of our proposed model.

Case 1. The surrounding rock stability assessment data for 5 samples [28, 29] are listed in Table 1. According to previous studies, stability of surrounding rock is usually divided into five levels $[28,29]$. And the assessment levels for stability of surrounding rock are shown in Table 2 . The weights of the indexes cited from [28] are as follows: $\mathbf{w}=$ $(0.241,0.198,0.145,0.197,0.219)$.

Let us take index $C_{1}$ of sample 1 as an example to demonstrate the specific calculation steps. The characteristic 


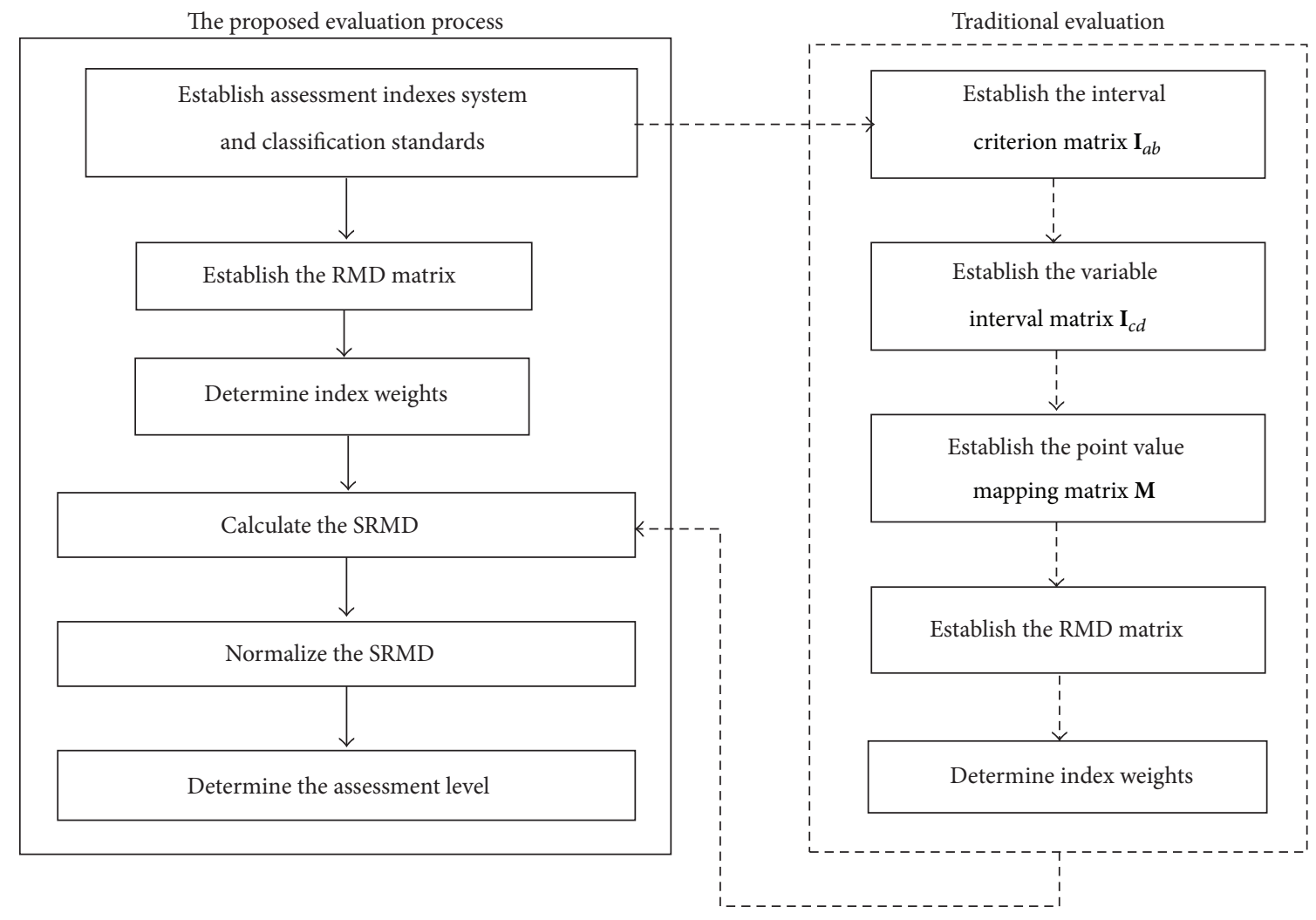

FIGURE 3: Evaluation flowchart of the proposed approach.

TABLE 2: Level standard to surrounding rock stability.

\begin{tabular}{lcccc}
\hline Stability level & $\begin{array}{c}\text { Rock mass } \\
\text { quality } C_{1}\end{array}$ & $\begin{array}{c}\text { Uniaxial compressive } \\
\text { strength } C_{2}(\mathrm{MPa})\end{array}$ & $\begin{array}{c}\text { Integrality degree of } \\
\text { rock mass } C_{3}\end{array}$ & $\begin{array}{c}\text { Groundwater percolation capacity } \\
C_{4}(\mathrm{~L} /(\mathrm{min} \cdot 10 \mathrm{~m}))\end{array}$ \\
\hline Very good I & $0-0.10$ & $200-300$ & $0.75-1.00$ & $0-5$ \\
Joint $C_{5}$
\end{tabular}

value of the rock mass quality $\left(C_{1}\right)$ of sample 1 is known as 0.12 , which belongs to the intervals $\left[a_{12}=0.1, b_{12}=0.25\right]$.

Step 1. Utilize (32) to calculate RMDs to levels I, II, and III respectively:

$$
\begin{aligned}
& \mu_{11}\left(C_{1}\right) \\
& =\exp \left\{-\left[\frac{\sqrt{-\ln 0.5}(0.12-0.5 \times(0+0.1))}{0-0.1}\right]^{2}\right\} \\
& =0.3686 \\
& \mu_{12}\left(C_{1}\right) \\
& =\exp \left\{-\left[\frac{2 \times \sqrt{-\ln 0.5}(0.12-0.5 \times(0.1+0.25))}{0.1-0.25}\right]^{2}\right\} \\
& =0.6888,
\end{aligned}
$$

$$
\begin{aligned}
& \mu_{13}\left(C_{1}\right) \\
& =\exp \left\{-\left[\frac{2 \times \sqrt{-\ln 0.5}(0.12-0.5 \times(0.25+0.4))}{0.25-0.4}\right]^{2}\right\} \\
& =0.0056
\end{aligned}
$$

According to VFS and (31)-(35), RMDs to levels IV and $\mathrm{V}$ are as follows:

$$
\begin{aligned}
& \mu_{14}\left(C_{1}\right)=0, \\
& \mu_{15}\left(C_{1}\right)=0 .
\end{aligned}
$$

The RMD vector was denoted by $\boldsymbol{\mu}_{1}$ as

$$
\boldsymbol{\mu}_{1}=(0.3686,0.6888,0.0056,0,0)
$$


TABLE 3: Results of case study and comparison.

\begin{tabular}{lccccc}
\hline Samples & $\begin{array}{c}\text { Proposed } \\
\text { model }\end{array}$ & $\begin{array}{c}\text { Basic quality } \\
\text { grading method [28] }\end{array}$ & $\begin{array}{c}\text { Variable fuzzy } \\
\text { set method [28] }\end{array}$ & $\begin{array}{c}\text { Triangular fuzzy } \\
\text { number method [29] }\end{array}$ & $\begin{array}{c}\text { Set pair-extenics } \\
\text { method [30] }\end{array}$ \\
\hline 1 & II & II & II & II & II \\
2 & II & II & II & II & II \\
3 & II & II & II & II & II \\
4 & I & I & I & I & I \\
5 & II & II & II & II & II \\
\hline
\end{tabular}

Similarly, we get the RMD vectors of the rest indexes to all levels. And the RMD matrix of sample 1 to every level is as follows:

$$
\boldsymbol{\mu}_{\text {sample 1 }}=\left[\begin{array}{ccccc}
0.3686 & 0.6888 & 0.0056 & 0 & 0 \\
0.4030 & 0.7051 & 0 & 0 & 0 \\
0.8744 & 0.0185 & 0 & 0 & 0 \\
0.3686 & 0.7792 & 0.1960 & 0 & 0 \\
0.0625 & 1 & 0.1458 & 0 & 0
\end{array}\right]
$$

Step 2. Using (5), the SRMD vectors of sample 1 to all levels are

$$
\begin{aligned}
& \boldsymbol{\beta}_{\text {sample } 1}=(0.3817,0.6808,0.0719,0,0) \\
& \boldsymbol{\beta}_{\text {sample } 1}=(0.3902,0.6627,0.0255,0,0) \\
& \quad(p=2, a=1) ; \\
& \boldsymbol{\beta}_{\text {sample 1 }}=(0.3361,0.7618,0.0006,0,0) ; \\
& \boldsymbol{\beta}_{\text {sample 1 }}=(0.2905,0.7943,0.0007,0,0) \\
& \quad(p=2, a=2) .
\end{aligned}
$$

Step 3. Using (13), the normal SRMD vectors of sample 1 are

$$
\begin{aligned}
& \boldsymbol{\beta}_{\text {sample 1 }}^{\prime}=(0.3365,0.6001,0.0634,0,0) \\
& \quad(p=1, a=1) ; \\
& \boldsymbol{\beta}_{\text {sample 1 }}^{\prime}=(0.3618,0.6145,0.0236,0,0) \\
& \quad(p=2, a=1) ; \\
& \boldsymbol{\beta}_{\text {sample 1 }}^{\prime}=(0.3059,0.6935,0.0006,0,0) \\
& \boldsymbol{\beta}_{\text {sample 1 }}^{\prime}=(0.2676,0.7318,0.0006,0,0) \\
& \quad(p=2, a=2) .
\end{aligned}
$$

Step 4. Utilizing (14), the average feature value for sample 1 is calculated as

$$
H_{\text {sample } 1}=1.704 .
$$

According to the level discriminant rule (15), sample 1 belongs to level 2. All the calculations are implemented in MS Excel worksheets.

Doing the same calculation to sample 1 to sample 5, the evaluation results of 5 samples are shown in Table 3. The surrounding rock stability levels of the five samples obtained by other four methods, that is, basic quality method [28], variable fuzzy set method [28], triangular fuzzy number method [29], and set pair-extenics method [30] were also listed in Table 3. It is obvious that the evaluation results of our approach are in a good agreement with that obtained by the other four methods. It suggests that our proposed approach is validated and reliable.

Case 2. The safety of a crane depends directly on its key systems or components. Crane metal structure approximately accounts for $60-70 \%$ of total weight [42]. Crane metal structure plays an important role in the whole machine and even determines the service life of the crane. Accurate analysis and evaluation of the safety state of the crane metal structure can effectively prevent accidents and reducing economic losses and provide useful quantitative information for the crane management departments.

Consider an application of the improved VFS model to crane metal structure safety assessment. The crane metal structure safety assessment is a synthetic evaluation and consists of many factors. Based on the previous studies [31], we selected crack $\left(C_{1}\right)$, strength $\left(C_{2}\right)$, stiffness $\left(C_{3}\right)$, deformation $\left(C_{4}\right)$, and corrosion $\left(C_{5}\right)$ as the evaluation indicators. Five levels of crane metal structure in the study include very good (I), good (II), fair (III), poor (IV), and very poor (V). Index classification standards [18] are listed in Table 4. Table 5 shows the dimensionless values of indicator and subjective weights obtained by AHP from a port crane [31]. Then, we proceed to use the proposed method to assess the port crane.

Step 1. Using (31)-(35), we get the RMD $\boldsymbol{\mu}_{\text {crane }}$ matrix as follows:

$$
\boldsymbol{\mu}_{\text {crane }}=\left[\begin{array}{ccccc}
0 & 0 & 0 & 0.8261 & 0.4356 \\
0.7759 & 0.0099 & 0 & 0 & 0 \\
0.3327 & 0.8524 & 0.0141 & 0 & 0 \\
0 & 0.3546 & 0.6581 & 0.0048 & 0 \\
0 & 0.0108 & 0.8071 & 0.2357 & 0
\end{array}\right]
$$


TABLE 4: Safety level for metal structure safety assessment of a port crane.

\begin{tabular}{lccccc}
\hline Safety level & Crack $\left(C_{1}\right)$ & Strength $\left(C_{2}\right)$ & Stiffness $\left(C_{3}\right)$ & Deformation $\left(C_{4}\right)$ & Corrosion $\left(C_{5}\right)$ \\
\hline Very good I & $0.9-1$ & $0.6-1$ & $0.8-1$ & $0.8-1$ & $0.8-1$ \\
Good II & $0.8-0.9$ & $0.4-0.6$ & $0.6-0.8$ & $0.6-0.8$ & $0.6-0.8$ \\
Fair III & $0.7-0.8$ & $0.25-0.4$ & $0.4-0.6$ & $0.4-0.6$ & $0.4-0.6$ \\
Poor IV & $0.5-0.7$ & $0.15-0.25$ & $0.2-0.4$ & $0.2-0.4$ & $0.2-0.4$ \\
Very poor V & $0-0.5$ & $0-0.15$ & $0-0.2$ & $0-0.2$ & $0-0.2$ \\
\hline
\end{tabular}

TABLE 5: Index assessment values and weights.

\begin{tabular}{lccccc}
\hline & Crack $\left(C_{1}\right)$ & Strength $\left(C_{2}\right)$ & Stiffness $\left(C_{3}\right)$ & Deformation $\left(C_{4}\right)$ & Corrosion $\left(C_{5}\right)$ \\
\hline Dimensionless values [31] & 0.5475 & 0.7580 & 0.7480 & 0.5777 & 0.4444 \\
Subjective weights (AHP) [31] & 0.561 & 0.2115 & 0.108 & 0.0713 & 0.0483 \\
Objective weights (entropy) & 0.1989 & 0.2495 & 0.1911 & 0.1693 & 0.1911 \\
\hline
\end{tabular}

Step 2. Utilize (16) and (17) to get the objective weight vector. To compare the assessment results to different weights, we also considered 5 subjective weights for the port crane [31]. Objective and subjective weights are both listed in Table 5, respectively.

Step 3. With the use of subjective weights [31] and (5), the SRMD vector denoted by $\boldsymbol{\beta}_{\text {crane }}$ is obtained. According to (13), normal SRMD denoted by $\boldsymbol{\beta}_{\text {crane }}^{\prime}$ is obtained and listed in Table 6.

Step 4. The average level's feature value is $H_{\text {crane }}=3.68$.

Step 5. According to the level discriminant rule (15), the assessment result is level IV.
Evaluation results of the port crane metal structure were listed in Table 8 . Using the subjective weight vector $\mathbf{W}=(0.561, \quad 0.2115, \quad 0.108, \quad 0.0713,0.0483)[31]$, the safety level feature value is 3.68 . That is to say, the safety of port crane structure belongs to level IV. Adopting the objective weight vector $\mathbf{W}=(0.1989,0.2495$, $0.1911,0.1693,0.1911)$, the safety level feature value is 2.58. The safety grade of port crane structure changes to level III. From the results given by the subjective and objective weight vectors, it can be conclude that the index sensibility is apparent.

To further test the feasibility of IVFS, VFS and SPA-VFS models were also employed for the port crane metal structure safety assessment. Here, we only present the brief assessment procedures of SPA-VFS method proposed in [23]. Its single index connection degree $v_{i h}$ can be calculated as follows:

$$
r_{i h}= \begin{cases}1-2\left|\frac{p_{i(h-1)}-x}{p_{i(h-1)}-p_{i(h-2)}}\right| & \text { if } x \text { locates in the adjacent } h-1 \text { grade } \\ 1-2\left|\frac{x-p_{i h}}{p_{i(h+1)}-p_{i h}}\right| & \text { if } x \text { locates in discussed } h \text { grade } \\ -1 & \text { if } x \text { locates in the adjacent } h+1 \text { grade }\end{cases}
$$

where $p_{i h}$ is extremum value of evaluation standard to level $h$. $x$ is characteristic value of $i$ th index. $i=1,2, \ldots, m, h=$ $1,2, \ldots, k . r_{i h}$ is the uncertainty component coefficients of discrepancy degree that represents the relation between $x$ and level $h$.

The RMD $\mu_{i h}$ between the $i$ th index and level $h$ is

$$
\mu_{i h}=0.5+0.5 \times r_{i h} .
$$

Step 1. With the use of (46), the single index connection degree matrix $\mathbf{r}_{\text {crane }}$ can be written as

$$
\mathbf{r}_{\text {crane }}=\left[\begin{array}{ccccc}
-1 & -1 & -0.525 & 1 & 0.525 \\
1 & 0.21 & -1 & -1 & -1 \\
0.48 & 1 & -0.48 & -1 & -1 \\
-1 & 0.777 & 1 & -0.777 & -1 \\
-1 & -0.556 & 1 & 0.556 & -1
\end{array}\right]
$$


TABLE 6: The RMD vector $\boldsymbol{\beta}_{\text {crane }}$ and SRMD vector $\boldsymbol{\beta}_{\text {crane }}^{\prime}$ of the port crane by IVFS.

\begin{tabular}{|c|c|c|c|c|c|c|c|c|c|c|}
\hline $\mathrm{a} \& \mathrm{p}$ & $\boldsymbol{\beta}_{\text {crane }}$ & & & & & $\boldsymbol{\beta}_{\text {crane }}^{\prime}$ & & & & \\
\hline$a=1, p=1$ & 0.2000 & 0.1199 & 0.0874 & 0.4751 & 0.2443 & 0.1775 & 0.1064 & 0.0776 & 0.4216 & 0.2168 \\
\hline$a=1, p=2$ & 0.2264 & 0.1368 & 0.0910 & 0.6329 & 0.3763 & 0.1547 & 0.0935 & 0.0622 & 0.4325 & 0.2571 \\
\hline$a=2, p=1$ & 0.0588 & 0.0182 & 0.0091 & 0.4504 & 0.0946 & 0.0932 & 0.0289 & 0.0144 & 0.7135 & 0.1500 \\
\hline$a=2, p=2$ & 0.0789 & 0.0245 & 0.0099 & 0.7482 & 0.2668 & 0.0699 & 0.0217 & 0.0088 & 0.6631 & 0.2365 \\
\hline
\end{tabular}

TABLE 7: The RMD vector $\boldsymbol{\beta}_{\text {crane }}$ and SRMD vector $\boldsymbol{\beta}_{\text {crane }}^{\prime}$ of the port crane by SPA-VFS.

\begin{tabular}{|c|c|c|c|c|c|c|c|c|c|c|}
\hline$a \& p$ & $\boldsymbol{\beta}_{\text {crane }}$ & & & & & $\boldsymbol{\beta}_{\text {crane }}^{\prime}$ & & & & \\
\hline$a=1, p=1$ & 0.2914 & 0.3100 & 0.2809 & 0.6065 & 0.4277 & 0.1520 & 0.1618 & 0.1466 & 0.3165 & 0.2232 \\
\hline$a=1, p=2$ & 0.2846 & 0.2398 & 0.2498 & 0.6956 & 0.5996 & 0.1375 & 0.1159 & 0.1207 & 0.3361 & 0.2897 \\
\hline$a=2, p=1$ & 0.1446 & 0.1679 & 0.1324 & 0.7037 & 0.3584 & 0.0960 & 0.1114 & 0.0878 & 0.4669 & 0.2378 \\
\hline$a=2, p=2$ & 0.1367 & 0.0905 & 0.0998 & 0.8393 & 0.6917 & 0.0736 & 0.0487 & 0.0537 & 0.4517 & 0.3723 \\
\hline
\end{tabular}

TABLE 8: Assessment results of port crane and comparison.

\begin{tabular}{|c|c|c|c|c|c|c|c|}
\hline \multirow{2}{*}{$\begin{array}{l}\text { Weighting } \\
\text { method }\end{array}$} & \multirow{2}{*}{$\begin{array}{l}\text { Evaluation } \\
\text { method }\end{array}$} & \multicolumn{4}{|c|}{ Ranking feature value } & \multirow{2}{*}{ Mean ranking feature value } & \multirow{2}{*}{ level } \\
\hline & & $a=1, p=1$ & $a=1, p=2$ & $a=2, p=1$ & $a=2, p=2$ & & \\
\hline \multirow{4}{*}{$\begin{array}{l}\text { Subjective weigh } \\
\text { (AHP) }\end{array}$} & Ref. [31] & & & & & & III \\
\hline & IVFS & 3.39 & 3.54 & 3.80 & 3.97 & 3.68 & IV \\
\hline & SPA-VFS & 3.29 & 3.52 & 3.64 & 4.00 & 3.62 & IV \\
\hline & VFS & 3.26 & 3.46 & 3.68 & 3.89 & 3.57 & IV \\
\hline \multirow{4}{*}{$\begin{array}{l}\text { Objective weigh } \\
\text { (entropy) }\end{array}$} & Ref. [31] & & & & & & II \\
\hline & IVFS & 2.66 & 2.73 & 2.44 & 2.48 & 2.58 & III \\
\hline & SPA-VFS & 2.66 & 2.77 & 2.46 & 3.13 & 2.75 & III \\
\hline & VFS & 2.63 & 2.70 & 2.51 & 2.44 & 2.57 & III \\
\hline
\end{tabular}

Step 2. Using (47), we transform $\mathbf{r}_{\text {crane }}$ to RMD matrix $\boldsymbol{\mu}_{\text {crane }}$

$$
\boldsymbol{\mu}_{\text {crane }}=\left[\begin{array}{ccccc}
0 & 0 & 0.2375 & 1 & 0.7625 \\
1 & 0.6050 & 0 & 0 & 0 \\
0.7400 & 1 & 0.2600 & 0 & 0 \\
0 & 0.8885 & 1 & 0.1115 & 0 \\
0 & 0.2220 & 1 & 0.7780 & 0
\end{array}\right]
$$

Step 3. With the use of subjective weights [31] and (5), the SRMD vector denoted by $\boldsymbol{\beta}_{\text {crane }}$ is obtained. According to (13), normal SRMD denoted by $\boldsymbol{\beta}_{\text {crane }}^{\prime}$ is obtained and listed in Table 7.

Step 4. The average level's feature value is $H_{\text {crane }}=3.62$.

Step 5. According to the level discriminant rule (15), the safety of port crane metal structure belongs to level IV.

For comparison, the results of port crane by various methods are all listed in Table 8 . From it, we can find that the results obtained by IVFS are in a good agreement with those given by SPA-VFS and VFS. The fundamental reason why the safety level given by IVFS is identical with that by VFS lies in the characteristics of IVFS membership function. As shown in Figure 2, the graph of IVFS membership function is similar to that of VFS membership function. The assessment results reflect the consistency of IVFS and VFS. It assumes that the results given by the proposed model are acceptable in crane safety level assessment. However, the safety levels of the port crane obtained by $\mathrm{Wu}$ and Shen [31] and this study are different. Take the results given by subjective weights, for example. The obtained assessment grades by IVFS, SPA-VFS, and VFS are IV, while the grade is level III by using AHP method in [31]. One reason is that AHP approach has not the ability to determine RMD. Another is that [31] adopted integral assessment standards leading to very crude level of the port crane. As a matter of fact, in many applications, crane metal structure evaluation standard is described by an interval such as the crack $\left(C_{1}\right)$ index, in which level II is $0.8-0.9$ and level III is $0.7-0.8$ (see Table 4 ). It is obvious that the IVFS, SPA-VFS, and VFS methods are all suitable for application in crane metal structure assessment for safety standard described by an interval and overcome the shortages of Wu's approach [31].

From a methodology point of view, VFS and SPA-VFS use the linear functions to describe the RMD, while ours adopts nonlinear functions, for example, normal membership function. Two cases illustrate the feasibility that traditional linear membership functions are replaced with normal membership ones. 


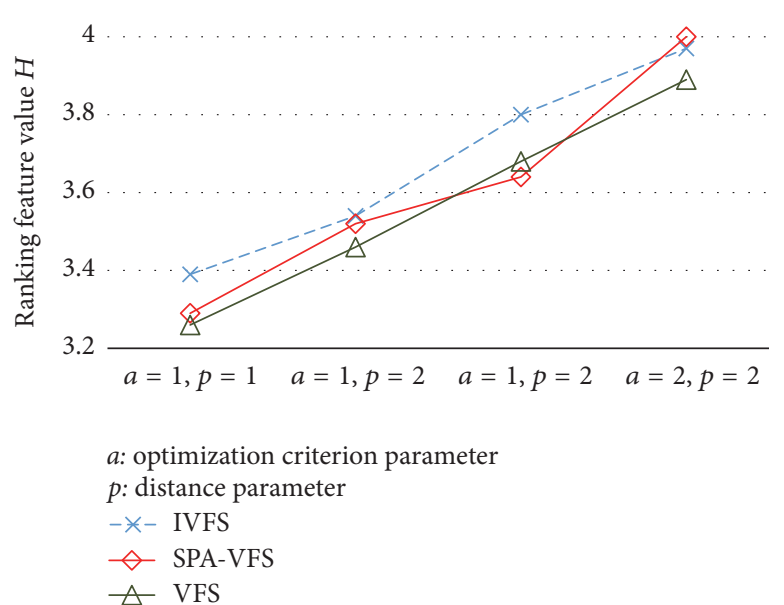

(a) Subjective weighting method (AHP)

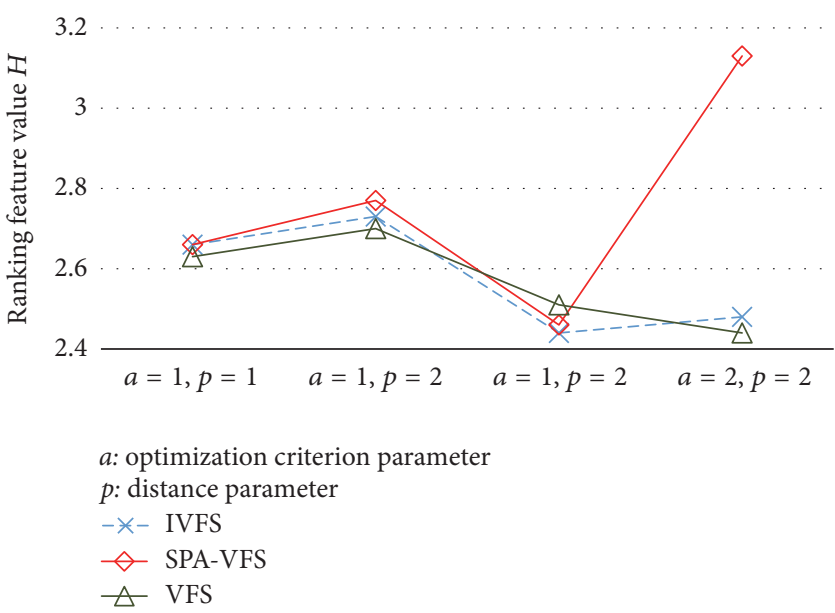

(b) Objective weighting method (entropy method)

FIGURE 4: The comparison of ranking feature values using IVFS, SPA-VFS, and VFS, respectively: (a) subjective weighting method and (b) objective weighting method.

According to the comparison shown in Figure 4, the curve of the ranking feature values determined by IVFS appears relatively smooth. On the whole, the two curves of the ranking feature values determined by IVFS and VFS are similar. It is consistent with the hypotheses in Section 3.2. The line of the ranking feature values determined by determined by SPA-VFS is more complicated than the other two. So it can be inferred that the level feature values obtained by IVFS and VFS are more stable than that by SPA-VFS.

In this study, we proposed IVF method for crane safety evaluation. Compared with Wu's method [31], VFS, and SPAVFS, the IVFS method has the merits as follows.

(1) Compared with Wu's method [31], IVF can deal with the evaluation problem of crane safety when crane risk standards are expressed in intervals.

(2) Compared with VFS, the IVFS method, by replacing traditional VFS membership function with normal membership function, does not need to select piecewise linear membership function to calculate RMD and thus simplifies assessment processes.

(3) Compared with SPA-VFS, the advantage of IVFS is validated as shown in Figure 4. That is, level feature values obtained by IVFS are more stable than that from SPAVFS. In addition, although SPA-VFS has the merit of simple computation over to VFS [43], the calculations of IVFS are even slightly concise and straightforward than those of SPAVFS which needs to transform connection degree matrix to RMD matrix.

Although normal membership function may look complicated, it can be solved by Microsoft Excel easily. Thus, it is not hard to see that our proposed model has some desirable advantages over the Wu's method [31], VFS, and SPA-VFS.

\section{Conclusions}

Crane safety evaluation is of great significance to reduce casualties and economic losses. Therefore, it has drawn close attention from scholars and engineering. However, previous crane safety evaluation models are not ideal for dealing with assessment standard described in terms of interval. This paper presents an improved VFS method so as to simplify the evaluation process with nonlinear membership function, for example, normal membership function, and applied it to evaluate crane safety when the criteria are expressed as intervals. Some conclusions are drawn as follows.

(1) This paper solves the assessment problem of crane safety when crane evaluation standards are described in intervals. Two cases including an application to port crane metal structure safety assessment have been examined using IVFS and demonstrated its superiorities and the detailed implementation process.

(2) The results show that the IVFS model is feasible for assessing the crane metal structure safety and convenient for practical applications. This proposed method may be an effective alternative approach for safety evaluation of other problems with no much modification.

No matter whether we use subjective or objective weights, the results obtained by IVFS are consistent with those given by VS and SPA-VFS. So it can provide a valuable reference for crane risk assessment. However, the results are based on relatively limited data samples. Thus, it is necessary to involve more empirical studies in future. In addition, Table 8 shows that the assessment levels given by subjective weights [31] and objective weights are different. Therefore, more rational weighting method should be considered in the future study.

\section{Competing Interests}

The authors declare that there is no conflict of interests regarding the publication of this paper.

\section{References}

[1] L. B. Zhu, X. Wu, and H. Chen, "Study on special equipment safety risk assessment and control measures," China Safety Science Journal, vol. 24, no. 1, pp. 149-155, 2014. 
[2] I. J. Shin, "Factors that affect safety of tower crane installation/dismantling in construction industry," Safety Science, vol. 72, pp. 379-390, 2015.

[3] M. Kawata, Safety Use of Cranes in the Construction Industry, Occupational Safety and Health Council, Hong Kong Special Administrative Region, 2007.

[4] AQSIQ (General Administration of Quality Supervision, Inspection and Quarantine of People's Republic of China), "A report on the national safety status of special equipment in 2015", 2016, http://www.aqsiq.gov.cn/xxgk_13386/tzdt/gzdt/201504/ t20150420_436720.htm.

[5] R. L. Neitzel, N. S. Seixas, and K. K. Ren, "A review of crane safety in the construction industry," Applied Occupational and Environmental Hygiene, vol. 16, no. 12, pp. 1106-1117, 2001.

[6] V. W. Y. Tam and I. W. H. Fung, "Tower crane safety in the construction industry: A Hong Kong Study," Safety Science, vol. 49, no. 2, pp. 208-215, 2011.

[7] J. B. Hu, G. W. Qing, H. F. Wang, and D. J. Ni, "Classification evaluation of bridge and gantry cranes based on fuzzy analytic hierarchy process," Journal of Safety Science and Technology, no. 5, pp. 187-192, 2014.

[8] Z. Y. Zhao, X. W. Liu, L. Su, and Y. D. Li, "Research on structural safety evaluation on shipbuilding crane based on FAHP method," Port Operation, no. 3, pp. 12-15, 2012.

[9] G. Xu and P. Li, "Comprehensive evaluation for safety working status of hoisting mechanism of crawler crane based on 3-scale AHP," Applied Mechanics and Materials, vol. 249-250, pp. 583588, 2013.

[10] R. G. Yang, G. N. Xu, and X. F. Shu, "On the crane safety assessment based on the unacertained measuring theory," Journal of Safety and Environment, vol. 11, no. 2, pp. 224-227, 2011.

[11] A.-H. Li and Z.-Y. Zhao, "Crane safety assessment based on game theory and uncertainty measurement theory," Journal of Dalian Maritime University, vol. 42, no. 3, pp. 77-83, 2016.

[12] Z. F. Chen and Q. S. Zhang, "The safety evaluation for gantry system of portal crane based on the grey theory and analytic hierarchy process," Journal of Fuzhou University (Natural Science Edition), vol. 41, no. 3, pp. 354-358, 2013.

[13] B. Li, D. F. Chen, D. X. Tao, Z. Y. Zhao, and S. J. Sun, "Crane safety evaluation based on neutral network," Hoisting and Conveying Machinery, no. 9, pp. 52-55, 2006.

[14] W. H. Wang, X. D. Meng, B. M. Qiang, and Y. Cao, "Research on index system and software system design of bridge crane safety evaluation," Journal of Safety Science and Technology, vol. 9, no. 9, pp. 155-159, 2013.

[15] W. J. Shu, G. F. Xu, G. Q. Wei, and Q. Fan, "Metal structure safety assessment of crane based on SVM," Machinery Design \& Manufacture, no. 12, pp. 269-272, 2014.

[16] A. H. Li and Z. Y. Zhao, "Crane safety assessment based on Fisher discriminance and analysis method," Hoisting and Conveying Machinery, no. 12, pp. 14-17, 2015.

[17] G. Y. Ding, "Crane risk analysis based on multilevel fuzzy comprehensive assessment method," Plant Maintenance Engineering, no. 8, pp. 10-11, 2015.

[18] L. Chen, Research on Damage Modes and Methods of Risk Analysis for Gantry Crane, Wuhan University of Technology, Wuhan, China, 2013.

[19] C. Shouyu and G. Yu, "Variable fuzzy sets and its application in comprehensive risk evaluation for flood-control engineering system," Fuzzy Optimization and Decision Making, vol. 5, no. 2, pp. 153-162, 2006.
[20] S. Y. Chen, Theory and Model of Engineering Variable Fuzzy Sets and Its Application, Dalian University of Technology Press, Dalian, China, 2009.

[21] Z. Dan, W. Guoli, and Z. Huicheng, "Assessment on agricultural drought risk based on variable fuzzy sets model," Chinese Geographical Science, vol. 21, no. 2, pp. 167-175, 2011.

[22] Y. Wang, D. Sheng, D. Wang, H. Ma, J. Wu, and F. Xu, "Variable fuzzy set theory to assess water quality of the meiliang bay in Taihu Lake Basi," Water Resources Management, vol. 28, no. 3, pp. 867-880, 2014.

[23] K.-Y. Wu, J.-L. Jin, Y.-L. Zhou, and W.-S. Wang, "Set pair analysis based variable fuzzy set assessment model for watershed water resources security," Journal of Sichuan University, vol. 40, no. 3, pp. 6-12, 2008.

[24] W.-J. Li, L. Qiu, X.-N. Chen, and Q. Huang, "Assessment model for river ecology health based on Set Pair Analysis and Variable Fuzzy Set," Journal of Hydraulic Engineering, vol. 42, no. 7, pp. 775-782, 2011.

[25] S. Y. Chen, "Fuzzy hydrology, Journal of Dalian University Technology, vol. 28, no. 1, pp. 93-97, 1988.

[26] S. Chen, "Relative membership function and new frame of fuzzy sets theory for pattern recognition," Journal of Fuzzy Mathematics, vol. 5, no. 2, pp. 401-411, 1997.

[27] L. A. Zadeh, "Fuzzy sets," Information and Control, vol. 8, no. 3, pp. 338-353, 1965.

[28] S. Chen and X. Han, "Engineering method of variable fuzzy set for assessment of surrounding rock stability," Chinese Journal of Rock Mechanics and Engineering, vol. 25, no. 9, pp. 1857-1861, 2006.

[29] M.-W. Wang, G.-Y. Chen, and J.-L. Jin, "Risk evaluation of surrounding rock stability based on stochastic simulation of multielement connection number and triangular fuzzy numbers," Chinese Journal of Geotechnical Engineering, vol. 33, no. 4, pp. 643-647, 2011.

[30] M. Wang, X. Xu, J. Li, J. Jin, and F. Shen, "A novel model of set pair analysis coupled with extenics for evaluation of surrounding rock stability," Mathematical Problems in Engineering, vol. 2015, Article ID 892549, 9 pages, 2015.

[31] Z. W. Wu and G. T. Shen, "A safety evaluation system for the cracked structural component of the port crane based on the analytic hierarchy process," Hoisting and Conveying Machinery, no. 4, pp. 7-10, 2016.

[32] S. Chen, Z. Xue, and M. Li, "Variable Sets principle and method for flood classification," Science China Technological Sciences, vol. 56, no. 9, pp. 2343-2348, 2013.

[33] S. Chen, Z. Xue, M. Li, and X. Zhu, "Variable sets method for urban flood vulnerability assessment," Science China Technological Sciences, vol. 56, no. 12, pp. 3129-3136, 2013.

[34] S.-Y. Chen and Z.-R. Wang, "Water resource systems' variable fuzzy sets evaluation new method based on the opposites unity and quantity-quality exchange theorem," Journal of Hydraulic Engineering, vol. 42, no. 3, pp. 253-270, 2011.

[35] C. E. Shannon, "A mathematical theory of communication," The Bell System Technical Journal, vol. 27, pp. 379-423, 1948.

[36] A. Malekian and A. Azarnivand, "Application of integrated Shannon's entropy and VIKOR techniques in prioritization of flood risk in the Shemshak watershed, Iran," Water Resources Management, vol. 30, no. 1, pp. 409-425, 2016.

[37] J. Tian, T. Liu, and H. Jiao, "Entropy weight coefficient method for evaluating intrusion detection systems," in Proceedings of the International Symposium on Electronic Commerce and Security (ISECS '08), August 2008. 
[38] Z.-H. Zou, Y. Yun, and J.-N. Sun, "Entropy method for determination of weight of evaluating indicators in fuzzy synthetic evaluation for water quality assessment," Journal of Environmental Sciences, vol. 18, no. 5, pp. 1020-1023, 2006.

[39] J. Guo, Y. Xiao, and H. Zhu, "A new method for fracturing wells reservoir evaluation in fractured gas reservoir," Mathematical Problems in Engineering, vol. 2014, Article ID 814284, 12 pages, 2014.

[40] D. Yin and T. Wu, "Optimizing well for fracturing by fuzzy analysis method of applying computer," in Proceedings of the 1st International Conference on Information Science and Engineering (ICISE '09), pp. 286-290, December 2009.

[41] S. Y. Chen, Z. C. Xue, M. Li, and D. Q. Wang, "Classification principle and method for quality of rock mass based on the variable sets," Journal of Engineering of Heilongjiang University, vol. 5, no. 4, pp. 1-7, 2014.

[42] J. Ding, H. Huang, D. S. Yuan, and W. P. Zhang, "Research on safety evaluation of port crane's metal structure," Port Operation, no. 5, pp. 7-11, 2011.

[43] Q. Zou, J. Zhou, C. Zhou, L. Song, and J. Guo, "Comprehensive flood risk assessment based on set pair analysis-variable fuzzy sets model and fuzzy AHP," Stochastic Environmental Research and Risk Assessment, vol. 27, no. 2, pp. 525-546, 2013. 


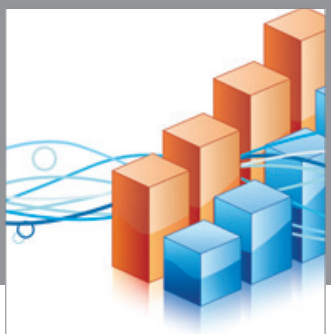

Advances in

Operations Research

vatem alat4

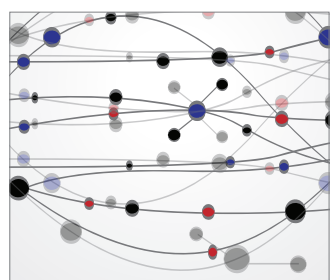

\section{The Scientific} World Journal
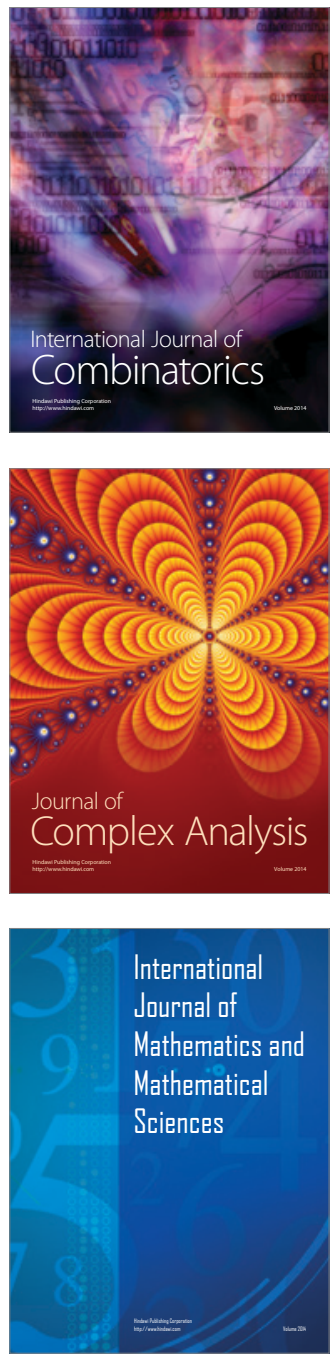
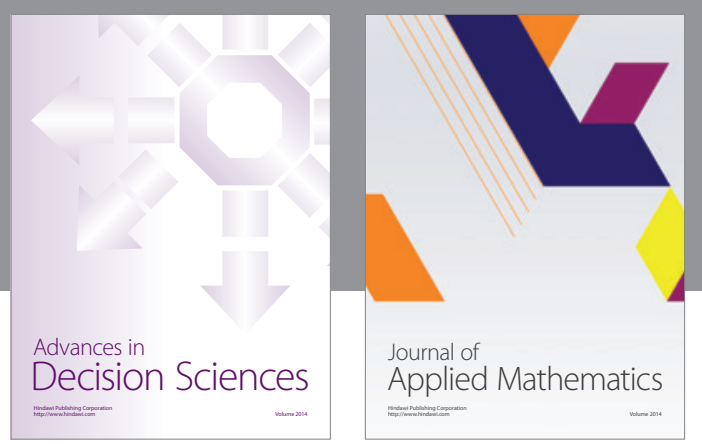

Algebra

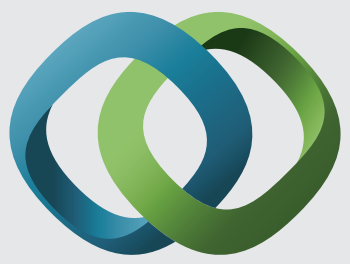

\section{Hindawi}

Submit your manuscripts at

https://www.hindawi.com
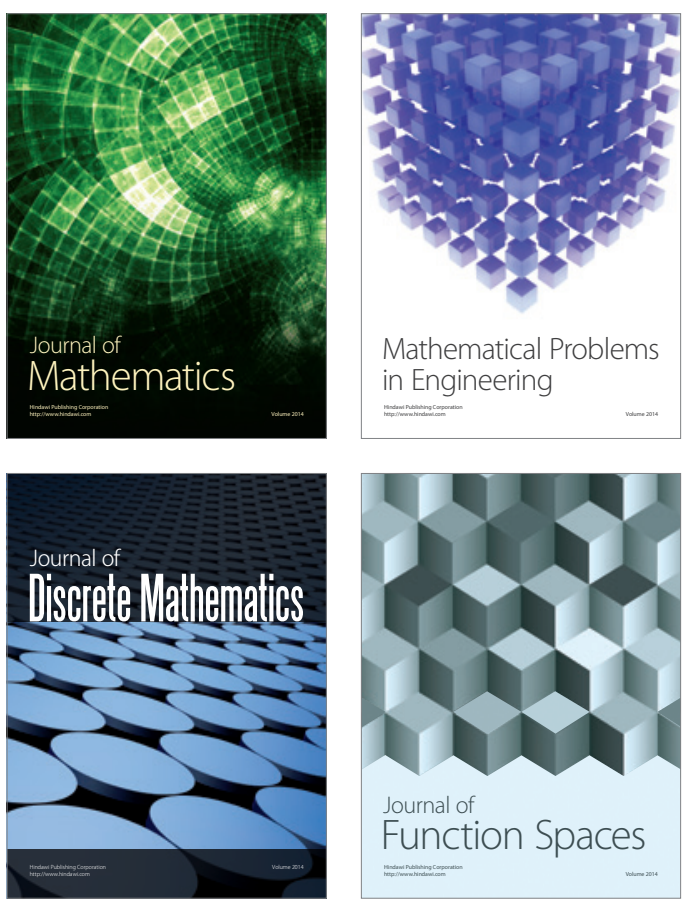

Mathematical Problems in Engineering
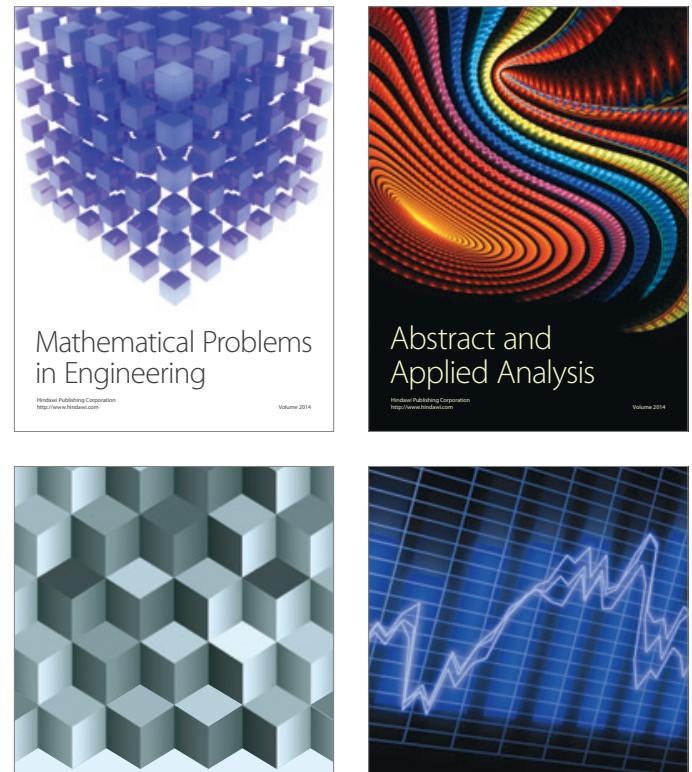

Journal of

Function Spaces

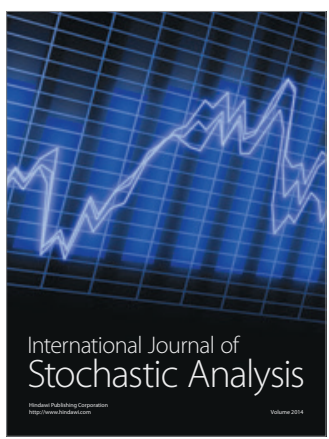

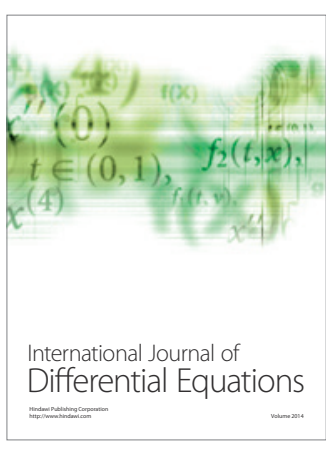
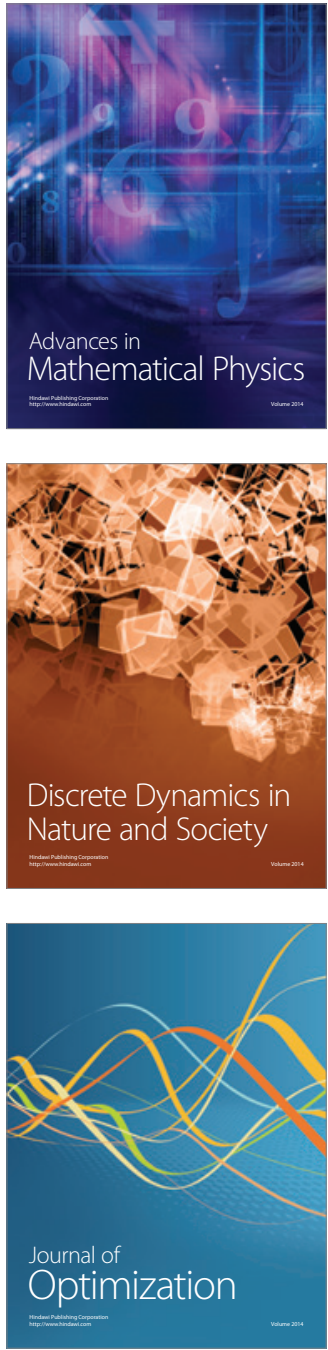